\title{
The Body Beyond Movement: (Missed) Opportunities to Engage with Contemporary Dance in $\mathrm{HCI}$
}

\author{
STEPHAN JÜRGENS, ITI/LARSyS, Portugal \\ NUNO N. CORREIA, University of Greenwich, UK and ITI/LARSyS, Portugal \\ RAUL MASU, ITI/LARSyS, Portugal and DI, FCT, Universidade Nova de Lisboa, Portugal
}

\begin{abstract}
This paper argues that a significant paradigm change in contemporary dance can offer further opportunities for HCI researchers interested in embodied interaction and interactive system design. Based on the analysis of $42 \mathrm{HCI}$ papers in our data set, resulting from searches in two computing research libraries, we suggest seven thematic categories that reflect how HCI researchers have been engaging with contemporary dance. Moreover, we propose a standardized usage of contemporary dance terminology in HCI literature, and discuss the current state of engagement with publications from the field of performance theory. We identify three opportunities for HCI, which can arise through further engagement with the knowledge produced in contemporary dance and performance: to engage with the field of embodied interaction from the perspective of performance research and theory; to employ contemporary dance methods and practices in HCI research; and to integrate contemporary dance choreographers and performers as researchers in interdisciplinary projects.
\end{abstract}

CCS Concepts: • Human-centered computing $\rightarrow$ HCI theory, concepts and models; • Applied computing $\rightarrow$ Performing arts.

Additional Key Words and Phrases: embodied interaction; contemporary dance; literature review; performance studies; interdisciplinarity; referencing

\section{INTRODUCTION}

There is an increasing interest from the HCI community in contemporary dance, often linked to the growing attention given to the concept of embodied interaction. Regarding the latter, an important milestone has been Dourish's book "Where the Action Is" [25], which set the foundation for embodied interaction in HCI as "interaction design for and with the lived body" [30]. More recently, Kirsh [42] has proposed concrete ideas how embodied cognition can enhance interaction design in HCI. Less prevalent in the HCI community is the acknowledgement of a significant paradigm change in contemporary dance. This shift is reflected in recent performance theory and the sub-field of dance studies: movement is not the sole medium of expression of the dancer anymore, and choreography is no longer understood exclusively as the organization of the movements of human bodies in space and time. Instead, much contemporary dance choreography can be described as a "collection and organization of heterogeneous materials, as an intermedial 
arrangement of bodies, spoken language, texts, images, light, sound and objects" [43]. In consequence, contemporary dance practitioners frequently develop novel skill sets to collaborate in interdisciplinary artistic and scientific projects as experts in embodied interaction (e.g. partaking in the development, testing and performing of interactive systems). In summary, the paradigm shift describes how contemporary dance has grown into a heterogeneous and interdisciplinary artistic field that is very different from traditional dance, and which offers HCI researchers new and distinct opportunities for engaging.

\subsection{Paradigm shift in Performance Theory}

The paradigm shift (i.e. the focus is not on movement exclusively any longer, but on the body and its multimodal forms of communication) also significantly expands traditional conceptions of dance and consequently challenges any "categorizing and historically unique classifications" of contemporary dance [18]. Today, performance theory and dance scholars explain contemporary dance as an artistic field that consists of many different dance practices or genres, including expressionist dance, modern dance, postmodern dance, contact improvisation, (neoclassical) ballet, Tanztheater (dance theater, physical theater) [44], and recently, self-reflexive postmodern dance and concept dance [43]. We propose to add to this list digital performance [24] and choreographic performance [21] as important contemporary dance practices or genres. Dancers (and choreographers) today train, create and perform in various genres of the field of contemporary dance: for example, they may combine ballet technique classes, somatic practices and dance theater techniques during a particular dance production. This led Lampert to conclude that the ideal body in contemporary dance today is a versatile, hybrid body [44]. Additionally, dance improvisation methods have become an integral part of contemporary dance practices since the 1950s [44]. As a result, the roles of choreographers and dancers in the creative process can be very different, ranging from traditional directorial approaches to co-creation type of collaborations. Dancers, who use improvisational systems and techniques in creation and/or in performance, are not only proficient in several dance techniques, but also know how to explore and employ compositional strategies. This skill set enables them to become 'artist-researchers', specialists in embodied interaction who can explore numerous environments through their bodies. Cvejic in her book "Choreographing Problems" refers to the work of choreographers Burrows and Ritsema as "dancing in the state of questioning," and their practice of dance improvisation as "progressively delineating their field of inquiry" [21]. Hybrid dance forms, intermedial choreographic processes and improvisation techniques represent great challenges for those HCI researchers who seek to classify dance and need to generalise their findings.

\subsection{Challenges and opportunities for $\mathrm{HCl}$}

For HCI researchers, the paradigm shift represents the challenge of engaging with the complexity of recent performance theory, which by nature is already interdisciplinary and in dialogue with recent theories from neurosciences (e.g. $[6,8,20])$, cognitive sciences (e.g. [3, 33, 34, 42]), media art philosophy (e.g. [5, 24, 51, 58]) and so forth. On the other hand, it is precisely the recently produced knowledge and practice of novel methods and techniques of artistic research in contemporary dance, which offer great opportunities for HCI researchers interested in embodied interaction. This perspective leads to our main research question, which will be addressed in the main sections of this paper:

How has HCI been engaging with contemporary dance? This main research question focuses on three specific aspects: a) Which are the main themes emerging in HCI when engaging with contemporary dance?; b) How do HCI researchers understand the term 'contemporary dance'? and c) How do the authors engage with literature from dance studies and performance theory? 
By answering the main research question, pathways to future development will also be suggested, leading to our secondary research question, which will be addressed in the final section of the paper:

What opportunities for HCI can arise through engagement with the paradigm shift in contemporary dance and performance theory?

\section{METHODS}

In order to answer our research question, we conducted searches within two of the main online libraries of HCI-related articles: ACM Digital Library and IEEE Xplore. We limited our search to these two major computing-related libraries since we wanted to specifically focus on how Contemporary Dance is viewed in HCI literature. We ruled out publications that did not mention our search "contemporary dance" term explicitly. The inclusion of other, more specific online libraries, and of related search terms (such as choreography and improvisation etc.) would have been beyond the scope of this paper. However, we clearly see potential for further future research into these topics. We searched the term "+Contemporary +Dance" in both libraries (on the 24th October 2019). In the ACM Digital Library, the search returned 47 results. In the IEEE Xplore, the search returned 17 results. We then filtered the results based on the following criteria: usage of the composite term 'contemporary dance' in the paper. This resulted in 44 papers: 35 from ACM Digital Library and 9 from IEEE. We then removed two additional articles that were considered not relevant: short articles presenting a talk (2 pages [19]) and a performance (only an image and caption [59]), resulting in the final 42 papers. We considered that the choice of the ACM and IEEE libraries, and the search terms, was successful in leading to results and a number of papers that allowed for adequate scope for our study. Our survey was informed by similar approaches within literature related to $\mathrm{HCI}$ and dance. Peng et al. [50] conducted a survey of dance in social robotics, taking as starting point mainly the IEEE online library, but also ACM Digital Library and others. Marshall et al. [46] analysed the quality of citations in a substantial sample of CHI 2016 publications. From the former, we adopted a similar study design. We adopted the latter's method of classification and rating of critique citations.

\section{WHICH ARE THE MAIN THEMES EMERGING IN HCI WHEN ENGAGING WITH CONTEMPORARY DANCE?}

Addressing the first aspect (a) of our main research question, we analysed the content of each of the 42 papers to identify their main topics. During the coding process of the papers, we looked for thematic clusters and eventually arrived at seven categories (see Table 1). Some papers could theoretically fall into more than one category, however, we decided to focus on the main contribution of each publication and allocated them in a single class.

\subsection{Results}

Out of 42 results, there were two categories with single articles, which we considered relevant enough not be grouped with others. Both of these papers represent important lines of research in the field (dance documentation and archives, and audience studies). Consequently, we added these two categories despite the low number of results. Within the remaining 40 papers there were always more than one result and the categories show clearly distinguishable topics. We also looked at the potential target group of the papers as we constituted the seven categories, as presented below under each category.

The first category presented, 'technical framework', encompasses papers presenting low-level technical contributions for developers. The category yields 9 results (21\%) and includes papers that contribute to new computational techniques, for example a visualisation system that exposes movement qualities for dance through rendering effects [1]; frameworks, 
Table 1. Main topics across 42 papers in seven categories

\begin{tabular}{lll}
\hline Category & N. papers (\%) & References \\
\hline C1.1 Technical framework & $9(21.4 \%)$ & [1], [4], [15], [26], [38], [48], [57], [63], [67] \\
C1.2 Research through practice & $8(19.0 \%)$ & {$[28],[29],[32],[35],[36],[53],[54],[56]$} \\
C1.3 Theory and methodology & $7(16.7 \%)$ & {$[2],[13],[16],[27],[37],[47],[55]$} \\
C1.4 Support tools for dance & $11(26.2 \%)$ & {$[10],[11],[12],[14],[17],[19]$, [22], [31], [60], [61], [64] } \\
C1.5 Artistic work and process & $5(11.9 \%)$ & {$[9],[40],[41],[49],[65]$} \\
C1.6 Dance archive / documentation & $1(2.4 \%)$ & {$[23]$} \\
C1.7 Audience studies & $1(2.4 \%)$ & [62] \\
\hline
\end{tabular}

e.g. MotionMachine, which helps with motion data interpretation through feature extraction and interactive visualisation [63]; and evaluation practices, for instance the feature evaluation and selection for phrase structure detection in dance [26]. For the most part these are low-level contributions that are not meant for end users but more likely for developers.

Category 1.2 includes papers that focus on the collaboration with dancers in an HCI research context, often with a user-centered design or co-design perspective. While some of the eight results (19\%) in this second category might also fit in the first category, the focus here was on a 'research through practice' approach towards dance, for example: research into embodied interaction through collaborative exploration and testing of interactive environments [29]; or transfer of ideas from two contemporary dance pieces to design of interactive furnishings [32].

Category 1.3 'theory and methodology' contains seven papers (17\%) that lay important theoretical and methodological ground for the field. For example, [47] is a theoretical paper discussing critical appropriations of biosensors in artistic practice, whereas [13] present important classifications of dance learning practices and movement principles towards developing a novel methodology for selecting motion capture data across different dance learning practices.

The fourth category 'support tools for dance' comprises eleven papers (26\%) presenting hardware and software solutions to support end users (choreographers, dancers, academic researchers and other dance professionals). Proposed support tools are designed for use in pedagogical environments [22, 31, 61], creation settings in dance e.g. [11, 17], or for dance analysis purposes, for example [14].

In category 1.5 , we find five papers $(12 \%)$ that focus on specific 'artistic work and processes' at the intersection of contemporary dance and various kinds of technologies, e.g. zero-gravity environments [9], interactive system design for the stage [40], or automatized and markerless motion capture for the creation of online scores [41]. This category is distinguishable from 1.2 as there is a stronger emphasis on the artistic side, and authors often present specific pieces.

As mentioned, the last two categories (1.6 'dance archive / documentation' and 1.7 'audience studies') were added, despite only containing a single paper each, because they represent significant research areas. The only paper in category 1.6 [23] presents multidisciplinary research in the context of an Intangible Cultural Heritage project [23]. This is clearly an area which includes several kinds of dance forms and genres (including contemporary dance) and their respective cultural and historical perspectives.

In the last category 1.7, a paper discusses audience behaviour during a contemporary dance performance based on a case study on a major contemporary dance company [62]. Again, the topic is addressed only once amongst the 42 papers, but represents an important research area and thus constitutes a category on its own. 


\subsection{Discussion}

Out of the 42 papers identified, $86 \%$ have been published in the last decade, indicating the strongly growing interest of HCI researchers in contemporary dance. Papers in category one 'technical framework' were the first to appear (from 2002 on), followed by publications on artistic work and process (2005 and later). Papers in the other five categories only start to appear since 2009 .

The most recent categories are 'research through practice' (papers since 2015) and 'theory and methodology' (from 2016 on). High percentages of total publications in these particular categories (35\% together) are certainly symptomatic of the paradigm change in contemporary dance discussed above (the body as an interface for interdisciplinary engagement). Moreover, the rapid succession of these publications also evidence novel forms and methods in HCI research, including changing models and roles of collaboration with the artists, and a growing interest in methods and theories related to embodied interaction [25,30]. Methodological and theoretical contributions can be outcomes of a larger research project $[13,27,55]$ and are sometimes followed by studies, which introduce the concrete application of these methodologies $[16,17]$.

This latter work in the context of larger research projects is mostly connected to category three 'support tools for dance', which is the biggest group of papers in our classification. Most support tools are carefully developed based on design specifications derived from the practice of a collaborating choreographer, or a small number of choreographers (up to six artists). Theoretical reflection upon these studies addresses key characteristics in the work of these choreographers from the perspective of $\mathrm{HCI}$ researchers, but generally does not engage with dance studies or performance theory (more of this anon). For example, authors present user testing of a support tool [12], although it would be helpful to research further into the continued use and appropriation of these tools by the dance community. In this context we suggest to consult a reference outside of our data set: Raheb et al. have recently presented a survey of 'dance interactive learning systems', which the authors organised in five categories of dance technology support tools [52]. Other authors in our data set look at contemporary dance and performance knowledge with the intention of transferring methods and approaches in order to apply these in HCI - for example: the aforementioned critical appropriations of biosensors in artistic practice in [47] and the transfer of ideas from contemporary dance pieces to the design of interactive furnishings [32]. The question of what contemporary dance has to offer $\mathrm{HCI}$ is intimately connected with the question of how contemporary dance is defined and what kind of work and knowledge is produced in the field that can be important for HCI.

\section{HOW DO HCI RESEARCHERS UNDERSTAND THE TERM 'CONTEMPORARY DANCE'?}

This question represents the second aspect (b) of our main research question, as outlined in the introduction. It is not a question that can be answered in a simple and straightforward fashion, because none of the papers we looked at offers a tentative definition of contemporary dance. Nor does any of the papers refer back to existing definitions in the literature of the related scientific areas, such as dance studies or performance theory. Hence, our method for analysis and coding was to compile a list with all descriptions of the term 'contemporary dance', characteristics attributed to it and relevant contextual information (e.g. do the authors discuss related art works, pedagogical situations, improvisational settings etc.). 
Table 2. Use of the term 'contemporary dance' (66 results across 42 papers, 20 papers fit more than one category)

\begin{tabular}{|c|c|c|}
\hline Category & N. papers (\%) & References \\
\hline C2.1 Contemporary dance as an artistic field & 19 papers $(28.8 \%)$ & $\begin{array}{l}{[1],[4],[9],[10],[11],[12],[19][22],[23],} \\
{[26],[36],[37],[40][41],[47],[49],[54],} \\
{[53],[65]}\end{array}$ \\
\hline C2.2 Contemporary dance as a dance genre & 24 papers $(36.4 \%)$ & $\begin{array}{l}\text { [1], [2], [9], [13], [14], [15], [16], [17], [23], } \\
{[27],[28],[29],[31],[38],[48],[55],[56],} \\
\text { [57], [60], [61], [62], [63], [64], [67] }\end{array}$ \\
\hline C2.3 Contemporary dance as a dance technique & 7 papers $(10.6 \%)$ & {$[15],[22],[56],[60],[61],[64],[67]$} \\
\hline $\begin{array}{l}\text { C2.4 Referring to artistic work in contemporary } \\
\text { dance }\end{array}$ & 10 papers $(15.2 \%)$ & $\begin{array}{l}{[4],[16],[17],[31],[32],[35],[40],[41],} \\
{[62],[65]}\end{array}$ \\
\hline $\begin{array}{l}\text { C2.5 Referring to processes and practices } \\
\text { in contemporary dance }\end{array}$ & 6 papers $(9.0 \%)$ & {$[4],[35],[37],[49],[64],[67]$} \\
\hline
\end{tabular}

\subsection{Results}

Based on these results, we established five categories in which 'contemporary dance' is used to describe: a field (2.1), a genre (2.2), or a technique (2.3). To deepen our analysis and subsequent discussion of the results, we also included references to concrete artistic work (2.4), and references to processes and practices (2.5). In this coding scheme, multiple mentions of papers in different categories were possible to analyze more precisely how the authors understood the term 'contemporary dance'. Across the 42 papers we obtained 66 results in five categories (Table 2).

Papers falling in category 2.1 use the term 'contemporary dance' as a general descriptor for an artistic field in the performing arts, for example [1, 19, 47, 53]. For Cabral et al. "contemporary dance is a domain", which is synonymous to "area" or "field" [10]. Dyaberi et al. use the term "western contemporary dance" [26], comparable to authors in performance theory literature who understand contemporary dance as a field.

In the second category, contemporary dance is understood as a genre, a kind, or as a style of dance that has its own terminology and can be distinguished from other genres, such as tango, folk dance or ballet [27]. Several authors who use the term in the sense of 'genre', mention the discourse of movement qualities as an essential topic in contemporary dance, e.g. [14, 27, 29, 31]. Some authors in this category perceive contemporary dance as a very challenging genre. For example, Aristidou et al. state: “(...) no two modern dancers perform the same as there is no routine steps, elements or styles (...) Contemporary dances are freeform motions that contain extreme postures" [2].

Category 2.3 consists of papers that use the term 'contemporary dance' as a synonym for a technique taught as a dance class, e.g. [56, 60], or as part of a dance curriculum, for example [22]. In this context, contemporary dance is described as "(...) a corporal practice that undoubtedly requires motor skills of the highest level. To reach expert level, dancers are trained to efficiently acquire complex movements and phrases" [56]. Out of seven results in this category, six also fall into category 2.2, indicating that contemporary dance as a technique is habitually associated with contemporary dance as a genre.

All ten results in category 2.4 are referring to artistic work in contemporary dance. Some authors have collaborated with well-established contemporary choreographers, e.g. [31, 41, 65], whose work is well-documented and represents distinct artistic approaches in the field. The remaining cases of presenting concrete artistic work are also very helpful for our analysis of what HCI researchers consider contemporary dance and why. For example, [4] presents several cases 
of collaborations between well-known media artists and choreographers to discuss the impact of digital technologies on contemporary dance.

Finally, category 2.5 consists of papers that address recent key topics in contemporary dance by looking at processes and practices. Hieda for instance presents a project where somatic practices are used as a technique to engage with mobile brain-computer interfaces in dance performances [35], and Hsueh et al. deconstruct the creative process and show how contemporary dance practitioners "invent and appropriate tools to achieve their desired ends" [37].

\subsection{Discussion}

Looking at Table 2 it is evident that the term 'contemporary dance' is not used in a homogeneous way. For less than a third of the authors, contemporary dance is an artistic field, while over a third of authors understand the term as a dance genre, or even narrower as a dance technique. As mentioned in the introduction section, all usages can make sense, according to the topic the researchers are investigating, and if identified properly. However, we suggest that a standardized usage for HCI terminology could employ a 'zooming in and out' type of logic: Contemporary Dance is an artistic field that consists of many different genres (sub-fields). Within each genre exists a set of techniques that is taught and practiced. Employing the explanation from Performance Theory presented in the introduction, HCI researchers can situate their specific topic on the respective level of detail through 'zooming' from the overall artistic field into the genre and even further into the techniques, or vice versa.

Moreover, our contextual analysis of all instances, in which the term contemporary dance was used across the 42 articles, shows that authors generally use the term as a mere descriptor of a field / a genre / a technique, without offering a definition or clarification of the term based on dance studies or performance theory (a notable exception is [53]). This leads to seemingly contradictory statements about what contemporary dance is, for instance in the citations we included in our descriptions of categories 2.2 and 2.3 above (i.e. [2] versus [56]).

The lack of clear contextualisation of the research topic within the broader field of contemporary dance produces additional problems for future HCI researchers who wish to build on the present research. Without a clear scope, research on specific aspects of contemporary dance will be mistaken to represent research of the entire field of contemporary dance. For example, some researchers assert that "movement qualities are central in contemporary dance" [31] or contend that "contemporary dance explores the qualities of movement and the mechanics of the human body" [14]. Within our dataset, we found that $82 \%$ of the papers ( 9 out of 11) that focus on movement qualities as a salient feature of contemporary dance, understand contemporary dance as a dance genre. In other words, future HCI researchers can be misled to think that movement qualities represent a central focus in all contemporary dance practice, which is far from reality, as we have shown in the introduction section. When contemporary dance is understood as a dance genre or technique, the claims made above can be considered an over-simplification, as many other important contemporary dance practices are excluded.

What is more, claims are often made without clarifying the target group (for example, for scholars, for professional dancers and choreographers, etc). For example, the two papers on movement qualities mentioned above [14, 31] do not specify for whom these movement qualities are central. If the target groups were defined from the outset of a study or paper, researchers would benefit from engaging with dance studies and performance theories, and assertions regarding the nature of contemporary dance (practices) would be differentiated to a great extent. 
Table 3. Number of papers with references related to performance studies

\begin{tabular}{lll}
\hline Category & N. papers $(\%)$ & References \\
\hline C3.1 Papers with 0\% related references & 13 papers $(31 \%)$ & {$[10],[11],[13],[19],[22],[29],[32],[38]$,} \\
& & {$[48],[61],[63],[65],[67]$} \\
C3.2 Papers with 0.1-20\% related references & 13 papers $(31 \%)$ & {$[2],[12],[17],[23],[26],[27],[28],[36]$,} \\
& & {$[37],[47],[56],[57],[64]$} \\
C3.3 Papers with 20.1-40\% related references & 9 papers $(21.3 \%)$ & {$[1],[4],[15],[16],[31],[35],[41],[55],[60]$} \\
C3.4 Papers with 40.1-60\% related references & 4 papers $(9.5 \%)$ & {$[14],[40],[54],[62]$} \\
C3.5 Papers with 60.1-80\% related references & 1 paper $(2.4 \%)$ & {$[53]$} \\
C3.6 Papers with 80.1-100\% related references & 2 papers $(4.8 \%)$ & {$[9],[49]$} \\
\hline
\end{tabular}

\section{HOW DO THE AUTHORS ENGAGE WITH LITERATURE FROM DANCE STUDIES AND PERFORMANCE THEORY?}

The third aspect (c) of our main research question (as outlined in the introduction) addresses the way the authors of the papers in our data set engaged with concepts and theories from performance theory, and whether the referenced theory was recent. We concluded from our analysis of the use of the term 'contemporary dance' that we needed to conduct a thorough study, which we present in this section of the paper.

\subsection{Results}

As a first step, we looked at all references of the 42 papers and determined, which are related to dance studies and performance theory. We found that out of the 896 references across the 42 papers, 156 can be related to dance studies and performance theory (17.4\%). We considered references to publications by dance and performance scholars in their field, and papers by scholars from a different field (e.g. neurosciences, linguistics or cognitive sciences) when published in performance theory venues. Table 3 shows the distribution of related references (156) across the total number of papers (42).

The results show that $31 \%$ of the authors do not become involved with dance and performance related theory at all. Further $31 \%$ show low numbers of related references (up to $20 \%$ ). Only seven papers (16.7\%) include more than $40 \%$ of related references in their paper.

As a second step in our analysis of the related references, we examined the kind of engagement with the dance study and performance theory literature. To this end, we employed a method by Marshall et al. [46], which they developed to study the quality of citations in a large sample of all CHI 2016 papers. The authors suggest five categories to evaluate citations (which we adopt in Table 4):

- List ("work is cited in a list, with no further comment or detail on the individual text");

- Work exists ("the citation is an example that work exists on this particular topic, with no further discussion. It is mentioned individually, not only in a list of other papers.");

- Supports a fact ("cited to justify a factual statement made. No detail or discussion is presented on research from which the fact is derived.");

- Described ("Work cited is described, including any of its justifications, methods and findings. The research is presented as valid and reliable"); and 
Table 4. Number of results (citation contexts, total =174) in Marshall and colleagues' five categories of citation

\begin{tabular}{lcc}
\hline Citation category & Results & $\%$ \\
\hline List & 21 & $12.1 \%$ \\
Work exists & 60 & $34.5 \%$ \\
Supports a fact & 26 & $14.9 \%$ \\
Described & 49 & $28.2 \%$ \\
Analysis / critique & 18 & $10.3 \%$ \\
\hline
\end{tabular}

Table 5. Occurrences of critique citations in papers

\begin{tabular}{lcc}
\hline Critique citations in paper & N. papers & $\%$ \\
\hline 0 citations & 35 & $83.3 \%$ \\
1 citation & 1 & $2.4 \%$ \\
2 citations & 3 & $7.1 \%$ \\
3 citations & 2 & $4.8 \%$ \\
4 citations & 0 & $0 \%$ \\
5 citations & 1 & $2.4 \%$ \\
\hline
\end{tabular}

- Analysis / critique ("the work reported in the cited paper, including any part of its justifications, methods and findings, is affirmed, contrasted, or contested.")

We adapted Marshall and colleagues' coding scheme and followed their analysis procedure closely, in order to evaluate our data set and eventually compare results. Two reviewers independently analysed 174 citation contexts, in which the 156 references appeared, and classified the citations according to the five categories described above. Inter-rater agreement was substantial (Cohen's $\kappa=0.69$ ). Table 4 shows the results in the respective categories of citation, while Table 5 displays the findings on critique citation in our data set.

Our analysis produced results that are positive on the one hand and disturbing on the other hand. The positive conclusions are: critique citation in our data set is more than twice as much (10.3\%) compared to Marshall et al. (4.8\%). All critique citation instances appear in papers from the last decade; and more than $80 \%$ of critique citations are very recent (between 2017 and 2019). Hopefully this constitutes a growing tendency. Nevertheless, Table 5 also shows an alarming result: $83.3 \%$ of all papers (35 of 42 ) contain no critique citations; only $16.7 \%$ contain critique citation. In comparison, Marshall et al. found 43\% papers lacking any critique citation in their data set [46].

\subsection{Discussion}

As Marshal et al. have alerted [46]:

"Lack of discussion and critique of previous work can encourage the spread of misunderstandings and errors. (...) failure to understand and discuss prior work is already leading directly to poor quality research. A particular risk is the citation of work from other fields, where CHI's tradition of citing as fact comes into conflict with complex and not easily summarised ideas from other disciplines."

In line with Marshall et al.'s findings, we have identified different types of problems, which can arise when contemporary dance related theory and concepts are introduced and employed without proper critical discussion. We will present examples of these problems, under each heading below. 
1) mis-interpretation of cited dance references: [64] claim: "In general, the twentieth-century history of dance as a performing art has two main choreographic trends: expressive methods and structural methods." The authors present some examples for their categories and reference Bremser and Sanders' edited book "Fifty Contemporary Choreographers" [7]. This publication however does not mention explicitly any such categories, nor does it support their viewpoint. On the contrary, the opening essay introduces several historical movements and forms of contemporary dance to discuss the existing multiplicity and variety of approaches.

2) unsupported claims and contradictions in HCI literature regarding dance references: [31] affirm that Laban Movement Analysis (LMA) is "a comprehensive language for movement description, representation, expression and performance extensively used in choreography." Their related reference [18] deals with Laban's modern educational dance and dates from 1963. There are no examples provided that clarify in what kind of choreography LMA is "extensively used". [27] on the contrary state that LMA "(...) is the most acceptable systematic model for analysing the qualitative aspects of dance by dance scholars, movement analysts, and movement computing experts, though it is not widely used by dance practitioners and dance teachers." While contradicting [31], there is no theoretical context provided, nor are examples given for the strong assertion.

3) idiosyncratic introduction of dance terms with potential for confusion: In their recent study on the creative process of six professional choreographers, [16] introduce the term "choreographic objects", which for the authors “(..) represent choreographic ideas that are manipulated throughout the entire process." In the field of performance studies however, choreographic objects are "not the same as the performance to which it relates. Choreographic objects attempt to provide a layer of analysis through an abstraction from the dances. They (...) disseminate dance knowledge across a wide community." [66]. Taking on the form of online graphic scores, navigable video content, or interactive multimedia installations (amongst other possibilities), such choreographic objects let the user partake in "thinking about choreographic thinking." [66].

While we find such examples even in the work of prolific writers in the field, there are also exemplary instances of critique citations. We present selected examples under the two types of good practice we identified in the sample.

1) clear theoretical contextualisation and scope: [37] state clearly what type and scope of performance theory they are referring to: "We are particularly interested in studies of choreography [14, 39] and music [16], which offer a different lens into the creative process," ${ }^{1}$ and explain how they will critically engage with the literature: "We build on these works to examine the use of artifacts in collaborative processes in music and dance: the relationships and forms of interactions that result, as well as their effect on creativity."

2) critical assessment based on presented references: [55] build their argument based on related references, critically assess the state of the art and identify their research context: "The literature on dance pedagogy is primarily focused either on the perspective of the teacher or on the impact of motor skill acquisition. However, discussion of the practical results of the techniques and mechanisms in play during the training of dancers is largely neglected in the literature. We propose that the study of dance movement acquisition should begin with an understanding of how dancers perceive their own learning pathways."

\section{OPPORTUNITIES FOR FURTHER ENGAGEMENT}

To answer our secondary research question, we will look at the types of opportunities, which arise from the engagement with the paradigm shift in contemporary dance outlined in the introduction section. Based on analysis of the 42 papers

${ }^{1}$ References in this citation are from the cited paper, not this one. 
in our data set, we suggest that three opportunities for HCI can arise through further engagement with the knowledge produced in contemporary dance and performance.

The first opportunity presents itself when engaging with the topic of embodied interaction from the perspective of performance research and theory. Seven papers in our data set address questions regarding embodied knowledge [13, 27], embodied interaction design [28, 29, 32, 37], or embodied cognition [56]. These papers are very recent (2016-2019) and indicate a growing interest in the topic, resonating with Kirsh: "The theory of embodied cognition can provide HCI practitioners and theorists with new ideas about interaction and new principles for better designs" [42]. In the field of performance theory and in related interdisciplinary research, there is a growing body of literature since the 1990s, when scholars started a still ongoing discussion regarding the virtual and live performers' bodies in relation to digital, robotic and sensorial technologies. We propose that looking into epistemologies and theories of embodiment from the perspective of performance theory is beneficial for HCI researchers who want to reflect critically on HCI methodologies and production.

A second opportunity arises from the use of recent contemporary dance methods and practices into more applied research areas within HCI, e.g. in the field of social robotics. In this field, researchers frequently draw on HCI literature, for example in order to implement models of dance movement analysis in the design of social robots [50]. Limiting the possibilities of a dancing robot to conventional movement computing (similar to the movement quality example discussed above) can result in poor design strategies. Instead, embodied practices for roboticists, such as recently proposed by LaViers et al. [45], benefit from including recent contemporary dance methods and practices (e.g. choreography as a body-based research system [21], or the use of somatic techniques and contact improvisation). In this example of applying recent contemporary dance methods and practices both, the researchers who practice the techniques in workshops, and the design process itself benefit from introducing this more recent knowledge.

Finally, the third opportunity resides in the integration of contemporary dance practitioners as researchers in interdisciplinary projects. In areas such as HCI research projects involving novel or recent sensorial technologies, contemporary choreographers and dancers can collaborate as in the role of experts in embodied interaction. For instance, Jürgens et al. have collaborated with a choreographer to systematically explore the limitations of a markerless motion capture system in a mixed reality performance. As a result, a typology of motion capture errors has been presented. This is an example of collaborative results which can be not only applied artistically, but also serve to improve the hardware and software components of a system [39].

\section{CONCLUSION}

In this paper, we have analyzed how HCI has engaged with contemporary dance, by addressing the three aspects of our main research question: a) Which are the main themes emerging in HCI when engaging with contemporary dance?; b) How do HCI researchers understand the term 'contemporary dance'? and c) How do the authors engage with literature from dance studies and performance theory? Regarding aspect a), we identified relevant recent topics, and suggested that the corresponding publications point at novel forms and methods in HCI research and a growing interest in embodied interaction. Relatively to aspect b), we proposed that a standardized usage for HCI terminology could employ a 'zooming in and out' type of logic. We also suggested that a definition of target groups would help future HCI researchers to engage with contemporary dance. Finally, by addressing aspect c), we detected a lack of critique citations (compared to a study analysing CHI literature [46]). We propose that there is a need for a better engagement with this field in HCI. 
We answered our secondary research question by identifying three opportunities arising from the engagement with the paradigm shift in contemporary dance: (1) to engage with the field of embodied interaction from the perspective of performance research and theory; (2) to employ contemporary dance methods and practices in HCI research and development; and (3) to integrate contemporary dance choreographers and performers as researchers in interdisciplinary projects.

Given the growing attention to embodied interaction theories in HCI, the opportunities identified above can be relevant for interaction design and beyond. They can contribute to rethinking embodied interaction - towards an expanded understanding of the body in its performative dimensions and actions. Regarding future work, we detect potential in complementing the present research with other approaches that engage with the paradigm shift in performance studies. That is, looking at the body beyond movement: from an embodied interaction perspective, shifting the focus from dance movement towards choreographic thinking and intermedial performance techniques.

\section{ACKNOWLEDGMENTS}

This research is co-funded by the Creative Europe programme of the EU (597398-CREA-1-2018-1-PT-CULT-COOP1, Moving Digits project). We acknowledge the support of LARSyS to this research (Projeto - UIDB/50009/2020). The third author acknowledges ARDITI - Agência Regional para o Desenvolvimento e Tecnologia (project M1420-09-5369-FSE000002 - PhD Studentship).

\section{REFERENCES}

[1] Rafael Kuffner dos Anjos, Claudia Ribeiro, and Carla Fernandes. 2018. Three-Dimensional Visualization of Movement Qualities in Contemporary Dance. In Proceedings of the 5th International Conference on Movement and Computing (MOCO '18). ACM, New York, NY, USA, 10:1-10:7. https: //doi.org/10.1145/3212721.3212812 Genoa, Italy.

[2] Andreas Aristidou, Qiong Zeng, Efstathios Stavrakis, KangKang Yin, Daniel Cohen-Or, Yiorgos Chrysanthou, and Baoquan Chen. 2017. Emotion Control of Unstructured Dance Movements. In Proceedings of the ACM SIGGRAPH / Eurographics Symposium on Computer Animation (SCA '17). ACM, New York, NY, USA, 9:1-9:10. https://doi.org/10.1145/3099564.3099566 Los Angeles, California.

[3] Philip Barnard and Scott deLahunta. 2017. Mapping the audit traces of interdisciplinary collaboration: bridging and blending between choreography and cognitive science. Interdisciplinary Science Reviews 42, 4 (Oct. 2017), 359-380. https://doi.org/10.1080/03080188.2017.1381226

[4] Angela Barnett. 2009. The Dancing Body As a Screen: Synchronizing Projected Motion Graphics Onto the Human Form in Contemporary Dance. Comput. Entertain. 7, 1 (Feb. 2009), 5:1-5:32. https://doi.org/10.1145/1486508.1486513

[5] Johannes H. Birringer. 2008. Performance, Technology, \& Science. PAJ Publications.

[6] Bettina Bläsing, Martin Puttke, and Thomas Schack. 2018. The Neurocognition of Dance (2 ed.). Routledge, London New York.

[7] Martha Bremser and Lorna Sanders. 2011. Fifty Contemporary Choreographers. Taylor \& Francis.

[8] Susan Broadhurst. 2007. Digital Practices: Aesthetic and Neuroesthetic Approaches to Performance and Technology. Springer.

[9] Annick Bureaud. 2009. Kitsou Dubois and the Weightless Body. IEEE MultiMedia 16, 1 (Jan. 2009), 4-7. https://doi.org/10.1109/MMUL.2009.12

[10] Diogo Cabral, Urândia Carvalho, João Silva, João Valente, Carla Fernandes, and Nuno Correia. 2011. Multimodal Video Annotation for Contemporary Dance Creation. In CHI '11 Extended Abstracts on Human Factors in Computing Systems (CHI EA '11). ACM, New York, NY, USA, 2293-2298. https://doi.org/10.1145/1979742.1979930 Vancouver, BC, Canada.

[11] Diogo Cabral, João Valente, João Silva, Urândia Aragão, Carla Fernandes, and Nuno Correia. 2011. A Creation-tool for Contemporary Dance Using Multimodal Video Annotation. In Proceedings of the 19th ACM International Conference on Multimedia (MM '11). ACM, New York, NY, USA, 905-908. https://oi.org/10.1145/2072298.2071899 Scottsdale, Arizona, USA.

[12] Diogo Cabral, João G. Valente, Urândia Aragão, Carla Fernandes, and Nuno Correia. 2012. Evaluation of a Multimodal Video Annotator for Contemporary Dance. In Proceedings of the International Working Conference on Advanced Visual Interfaces (AVI '12). ACM, New York, NY, USA, 572-579. https://doi.org/10.1145/2254556.2254663 Capri Island, Italy.

[13] Antonio Camurri, Katerina El Raheb, Oshri Even-Zohar, Yannis Ioannidis, Amalia Markatzi, Jean-Marc Matos, Edwin Morley-Fletcher, Pablo Palacio, Muriel Romero, Augusto Sarti, Stefano Di Pietro, Vladimir Viro, and Sarah Whatley. 2016. WhoLoDancE: Towards a Methodology for Selecting Motion Capture Data Across Different Dance Learning Practice. In Proceedings of the 3rd International Symposium on Movement and Computing (MOCO '16). ACM, New York, NY, USA, 43:1-43:2. https://doi.org/10.1145/2948910.2948912 Thessaloniki, GA, Greece.

[14] K. Carlson, T. Schiphorst, and C. Shaw. 2011. ActionPlot: A Visualization Tool for Contemporary Dance Analysis. In Proceedings of the International Symposium on Computational Aesthetics in Graphics, Visualization, and Imaging (CAe '11). ACM, New York, NY, USA, 113-120. https://doi.org/10. 
1145/2030441.2030466 Vancouver, British Columbia, Canada.

[15] Marta Castañer, Carlota Torrents, Gaspar Morey, M. Teresa Anguera, and Toni Jofre. 2010. Appraising the Aesthetics of Human Movement: An Application to Contemporary Dance Using a Motion Capture System. In Proceedings of the 7th International Conference on Methods and Techniques in Behavioral Research (MB '10). ACM, New York, NY, USA, 16:1-16:3. https://doi.org/10.1145/1931344.1931360 Eindhoven, The Netherlands.

[16] Marianela Ciolfi Felice, Sarah Fdili Alaoui, and Wendy E. Mackay. 2016. How Do Choreographers Craft Dance?: Designing for a ChoreographerTechnology Partnership. In Proceedings of the 3rd International Symposium on Movement and Computing (MOCO '16). ACM, New York, NY, USA, 20:1-20:8. https://doi.org/10.1145/2948910.2948941 Thessaloniki, GA, Greece.

[17] Marianela Ciolfi Felice, Sarah Fdili Alaoui, and Wendy E. Mackay. 2018. Knotation: Exploring and Documenting Choreographic Processes. In Proceedings of the 2018 CHI Conference on Human Factors in Computing Systems (CHI '18). ACM, New York, NY, USA, 448:1-448:12. https: //doi.org/10.1145/3173574.3174022 Montreal QC, Canada.

[18] Reto Clavadetscher and Claudia Rosiny (Eds.). 2007. Zeitgenössischer Tanz: Körper - Konzepte - Kulturen; eine Bestandsaufnahme. Number 10 in TanzScripte. Transcript-Verl, Bielefeld.

[19] Nuno Correia. 2013. Designing and Developing Interactive Multimedia Applications. In Proceedings of the 19th Brazilian Symposium on Multimedia and the Web (WebMedia '13). ACM, New York, NY, USA, 5-6. https://doi.org/10.1145/2526188.2528281 Salvador, Brazil.

[20] Emily S. Cross and Luca F. Ticini. 2012. Neuroaesthetics and beyond: new horizons in applying the science of the brain to the art of dance. Phenomenology and the Cognitive Sciences 11, 1 (March 2012), 5-16. https://doi.org/10.1007/s11097-010-9190-y

[21] Bojana Cvejic. 2016. Choreographing Problems: Expressive Concepts in Contemporary Dance and Performance. Palgrave Macmillan, New York.

[22] Sofia B. Dias, Leontios J. Hadjileontiadis, and José A. Diniz. 2014. On enhancing blended-learning scenarios through fuzzy logic-based modeling of users' LMS quality of interaction the rare contemporary dance paradigms. In 2014 International Conference on Computer Vision Theory and Applications (VISAPP), Vol. 2. 765-772.

[23] Kosmas Dimitropoulos, Sotiris Manitsaris, Filareti Tsalakanidou, Spiros Nikolopoulos, Bruce Denby, Samer Al Kork, Lise Crevier-Buchman, Claire Pillot-Loiseau, Martine Adda-Decker, Stephane Dupont, Joelle Tilmanne, Michela Ott, Marilena Alivizatou, Erdal Yilmaz, Leontios Hadjileontiadis, Vassilios Charisis, Olivier Deroo, Athanasios Manitsaris, Ioannis Kompatsiaris, and Nikos Grammalidis. 2014. Capturing the intangible an introduction to the i-Treasures project. In 2014 International Conference on Computer Vision Theory and Applications (VISAPP), Vol. 2. 773-781.

[24] Steve Dixon. 2007. Digital Performance: A History of New Media in Theater, Dance, Performance Art, and Installation. MIT Press.

[25] Paul Dourish. 2004. Where the Action Is: The Foundations of Embodied Interaction (new ed edition ed.). The MIT Press, Cambridge, Mass.

[26] Vidyarani M. Dyaberi, Hari Sundaram, Jodi James, and Gang Qian. 2004. Phrase Structure Detection in Dance. In Proceedings of the 12th Annual ACM International Conference on Multimedia (MULTIMEDIA '04). ACM, New York, NY, USA, 332-335. https://doi.org/10.1145/1027527.1027604 New York, NY, USA.

[27] Katerina El Raheb, Sarah Whatley, and Antonio Camurri. 2018. A Conceptual Framework for Creating and Analyzing Dance Learning Digital Content. In Proceedings of the 5th International Conference on Movement and Computing (MOCO '18). ACM, New York, NY, USA, 2:1-2:8. https: //doi.org/10.1145/3212721.3212837 Genoa, Italy.

[28] Cumhur Erkut and Sofia Dahl. 2017. Embodied Interaction Through Movement in a Course Work. In Proceedings of the 4th International Conference on Movement Computing (MOCO '17). ACM, New York, NY, USA, 23:1-23:8. https://doi.org/10.1145/3077981.3078026 London, United Kingdom.

[29] Cumhur Erkut and Anu Rajala-Erkut. 2015. Beyond Command \& Control: Sketching Embodied Interaction. In Proceedings of the 33rd Annual ACM Conference Extended Abstracts on Human Factors in Computing Systems (CHI EA '15). ACM, New York, NY, USA, 1681-1686. https://doi.org/10.1145/ 2702613.2732855 Seoul, Republic of Korea.

[30] Sarah Fdili Alaoui. 2019. Making an Interactive Dance Piece: Tensions in Integrating Technology in Art. In Proceedings of the 2019 on Designing Interactive Systems Conference (DIS '19). ACM, New York, NY, USA, 1195-1208. https://doi.org/10.1145/3322276.3322289 San Diego, CA, USA.

[31] Sarah Fdili Alaoui, Frederic Bevilacqua, and Christian Jacquemin. 2015. Interactive Visuals As Metaphors for Dance Movement Qualities. ACM Trans. Interact. Intell. Syst. 5, 3 (Sept. 2015), 13:1-13:24. https://doi.org/10.1145/2738219

[32] Keith Evan Green. 2019. Strange Places: Loci of Design Inspiration. In Proceedings of the Thirteenth International Conference on Tangible, Embedded, and Embodied Interaction (TEI '19). ACM, New York, NY, USA, 173-180. https://doi.org/10.1145/3294109.3300998 Tempe, Arizona, USA.

[33] Robin Grove, Catherine Stevens, and Shirley McKechnie. 2005. Thinking in Four Dimensions: Creativity and Cognition in Contemporary Dance. Thinking in Four Dimensions: Creativity and Cognition in Contemporary Dance (2005), vii. http://search.informit.com.au/documentSummary; dn= 018054756362361; res=IELHSS

[34] Pil Hansen and Bettina Bläsing. 2017. Performing the Remembered Present: The Cognition of Memory in Dance, Theatre and Music. Bloomsbury Publishing

[35] Naoto Hieda. 2017. Mobile Brain-Computer Interface for Dance and Somatic Practice. In Adjunct Publication of the 30th Annual ACM Symposium on User Interface Software and Technology (UIST '17). ACM, New York, NY, USA, 25-26. https://doi.org/10.1145/3131785.3131803 Québec City, QC, Canada.

[36] Michaela Honauer. 2018. Designing a Remote-Controlled Interactive Dance Costume. In Proceedings of the 5th International Conference on Movement and Computing (MOCO '18). ACM, New York, NY, USA, 40:1-40:6. https://doi.org/10.1145/3212721.3212879 Genoa, Italy.

[37] Stacy Hsueh, Sarah Fdili Alaoui, and Wendy E. Mackay. 2019. Deconstructing Creativity: Non-Linear Processes and Fluid Roles in Contemporary Music and Dance. Proc. ACM Hum.-Comput. Interact. 3, CSCW (Nov. 2019), 203:1-203:21. https://doi.org/10.1145/3359305 
[38] Stuart James, Manuel J. Fonseca, and John Collomosse. 2014. ReEnact: Sketch Based Choreographic Design from Archival Dance Footage. In Proceedings of International Conference on Multimedia Retrieval (ICMR '14). ACM, New York, NY, USA, 313:313-313:320. https://doi.org/10.1145/ 2578726.2578766 Glasgow, United Kingdom.

[39] Stephan Jürgens, Nuno N. Correia, and Raul Masu. 2020. Designing Glitch Procedures and Visualisation Workflows for Markerless Live Motion Capture of Contemporary Dance. In Proceedings of the 7th International Conference on Movement and Computing (MOCO '20). Association for Computing Machinery, Jersey City/Virtual, NJ, USA, 1-8. https://doi.org/10.1145/3401956.3404225

[40] Wolf Ka. 2005. Man in , e, Space.Mov / Motion Analysis in 3D Space. In Proceedings of the 13th Annual ACM International Conference on Multimedia (MULTIMEDIA '05). ACM, New York, NY, USA, 590-593. https://doi.org/10.1145/1101149.1101285 Hilton, Singapore.

[41] Svenja Kahn, Jens Keil, Benedikt Müller, Ulrich Bockholt, and Dieter W. Fellner. 2013. Capturing of contemporary dance for preservation and presentation of choreographies in online scores. In 2013 Digital Heritage International Congress (DigitalHeritage), Vol. 1. 273-280. https: //doi.org/10.1109/DigitalHeritage.2013.6743750

[42] David Kirsh. 2013. Embodied cognition and the magical future of interaction design. ACM Transactions on Computer-Human Interaction 20, 1 (April 2013), 3:1-3:30. https://doi.org/10.1145/2442106.2442109

[43] Gabriele Klein. 2015. Choreografischer Baukasten. Das Buch. transcript Verlag, Bielefeld. https://www.transcript-verlag.de/978-3-8376-31869/choreografischer-baukasten.-das-buch/

[44] Friederike Lampert. 2015. Tanzimprovisation: Geschichte - Theorie - Verfahren - Vermittlung. transcript Verlag.

[45] Amy LaViers, Catie Cuan, Catherine Maguire, Karen Bradley, Kim Brooks Mata, Alexandra Nilles, Ilya Vidrin, Novoneel Chakraborty, Madison Heimerdinger, Umer Huzaifa, Reika McNish, Ishaan Pakrasi, and Alexander Zurawski. 2018. Choreographic and Somatic Approaches for the Development of Expressive Robotic Systems. Arts 7, 2 (June 2018), 11. https://doi.org/10.3390/arts7020011

[46] Joe Marshall, Conor Linehan, Jocelyn Spence, and Stefan Rennick Egglestone. 2017. Throwaway Citation of Prior Work Creates Risk of Bad HCI Research. In Proceedings of the 2017 CHI Conference Extended Abstracts on Human Factors in Computing Systems (CHI EA '17). ACM, New York, NY, USA, 827-836. https://doi.org/10.1145/3027063.3052751 Denver, Colorado, USA.

[47] Teoma J. Naccarato and John MacCallum. 2017. Critical Appropriations of Biosensors in Artistic Practice. In Proceedings of the 4th International Conference on Movement Computing (MOCO '17). ACM, New York, NY, USA, 3:1-3:7. https://doi.org/10.1145/3077981.3078053 London, United Kingdom.

[48] Radoslaw Niewiadomski, Maurizio Mancini, Stefano Piana, Paolo Alborno, Gualtiero Volpe, and Antonio Camurri. 2017. Low-intrusive Recognition of Expressive Movement Qualities. In Proceedings of the 19th ACM International Conference on Multimodal Interaction (ICMI '17). ACM, New York, NY, USA, 230-237. https://doi.org/10.1145/3136755.3136757 Glasgow, UK.

[49] Foteini Papadopoulou and Martin Schulte. 2016. Movement Notation and Digital Media Art in the Contemporary Dance Practice: Aspects of the Making of a Multimedia Dance Performance. In Proceedings of the 3rd International Symposium on Movement and Computing (MOCO '16). ACM, New York, NY, USA, 8:1-8:7. https://doi.org/10.1145/2948910.2948929 Thessaloniki, GA, Greece.

[50] Hua Peng, Changle Zhou, Huosheng Hu, Fei Chao, and Jing Li. 2015. Robotic Dance in Social Robotics-A Taxonomy. IEEE Transactions on Human-Machine Systems 45, 3 (June 2015), 281-293. https://doi.org/10.1109/THMS.2015.2393558

[51] Simon Penny. 2017. Making Sense: Cognition, Computing, Art, and Embodiment. MIT Press. Google-Books-ID: U8mpAQAACAAJ.

[52] Katerina El Raheb, Marina Stergiou, Akrivi Katifori, and Yannis Ioannidis. 2019. Dance Interactive Learning Systems: A Study on Interaction Workflow and Teaching Approaches. Comput. Surveys 52, 3 (June 2019), 50:1-50:37. https://doi.org/10.1145/3323335

[53] Claudia Ribeiro, Rafael Kuffner dos Anjos, and Carla Fernandes. 2017. Capturing and Documenting Creative Processes in Contemporary Dance. In Proceedings of the 4th International Conference on Movement Computing (MOCO '17). ACM, New York, NY, USA, 7:1-7:7. https://doi.org/10.1145/ 3077981.3078041 London, United Kingdom.

[54] Claudia Ribeiro, Rafael Kuffner, Carla Fernandes, and João Pereira. 2016. 3D Annotation in Contemporary Dance: Enhancing the Creation-Tool Video Annotator. In Proceedings of the 3rd International Symposium on Movement and Computing (MOCO '16). ACM, New York, NY, USA, 41:1-41:4. https://doi.org/10.1145/2948910.2948961 Thessaloniki, GA, Greece.

[55] Jean-Philippe Rivière, Sarah Fdili Alaoui, Baptiste Caramiaux, and Wendy E. Mackay. 2018. How Do Dancers Learn To Dance?: A First-person Perspective of Dance Acquisition by Expert Contemporary Dancers. In Proceedings of the 5th International Conference on Movement and Computing (MOCO '18). ACM, New York, NY, USA, 6:1-6:7. https://doi.org/10.1145/3212721.3212723 Genoa, Italy.

[56] Jean-Philippe Rivière, Sarah Fdili Alaoui, Baptiste Caramiaux, and Wendy E. Mackay. 2019. Capturing Movement Decomposition to Support Learning and Teaching in Contemporary Dance. Proc. ACM Hum.-Comput. Interact. 3, CSCW (Nov. 2019), 86:1-86:22. https://doi.org/10.1145/3359188

[57] A.P. Ruiz and B. Vachon. 2002. Three learning systems in the reconnaissance of basic movements in contemporary dance. In Proceedings of the 5th Biannual World Automation Congress, Vol. 13. 189-194. https://doi.org/10.1109/WAC.2002.1049543

[58] Chris Salter. 2010. Entangled: Technology and the Transformation of Performance. MIT Press.

[59] Lien Fan Shen, Satu Hummasti, and H. James de St. Germain. 2008. Ghost Interruption. In ACM SIGGRAPH ASIA 2008 Artgallery: Emerging Technologies (SIGGRAPH Asia '08). ACM, New York, NY, USA, 26-26. https://doi.org/10.1145/1504229.1504247 Singapore.

[60] Asako Soga, Bin Umino, and Motoko Hirayama. 2009. Automatic Composition for Contemporary Dance Using 3D Motion Clips: Experiment on Dance Training and System Evaluation. In 2009 International Conference on CyberWorlds. 171-176. https://doi.org/10.1109/CW.2009.37

[61] Asako Soga, Yuho Yazaki, Bin Umino, and Motoko Hirayama. 2016. Body-part Motion Synthesis System for Contemporary Dance Creation. In ACM SIGGRAPH 2016 Posters (SIGGRAPH '16). ACM, New York, NY, USA, 29:1-29:2. https://doi.org/10.1145/2945078.2945107 Anaheim, California. 
[62] Lida Theodorou, Patrick G. T. Healey, and Fabrizio Smeraldi. 2016. Exploring Audience Behaviour During Contemporary Dance Performances. In Proceedings of the 3rd International Symposium on Movement and Computing (MOCO '16). ACM, New York, NY, USA, 7:1-7:7. https://doi.org/10. 1145/2948910.2948928 Thessaloniki, GA, Greece.

[63] Mickaël Tits, Joëlle Tilmanne, and Nicolas d'Alessandro. 2016. A Novel Tool for Motion Capture Database Factor Statistical Exploration. In Proceedings of the 3rd International Symposium on Movement and Computing (MOCO '16). ACM, New York, NY, USA, 2:1-2:8. https://doi.org/10.1145/2948910. 2948923 Thessaloniki, GA, Greece.

[64] Bin Umino, Asako Soga, and Motoko Hirayama. 2014. Feasibility Study for Contemporary Dance E-Learning: An Interactive Creation Support System Using 3D Motion Data. In 2014 International Conference on Cyberworlds. 71-76. https://doi.org/10.1109/CW.2014.18

[65] Tatsuo Unemi, Yoshiaki Matsui, and Daniel Bisig. 2008. Identity SA 1.6: An Artistic Software That Produces a Deformed Audiovisual Reflection Based on a Visually Interactive Swarm. In Proceedings of the 2008 International Conference on Advances in Computer Entertainment Technology (ACE '08). ACM, New York, NY, USA, 297-300. https://doi.org/10.1145/1501750.1501821 Yokohama, Japan.

[66] Sarah Whatley. 2017. Transmitting, Transforming, and Documenting Dance in the Digital Environment: What Dance Does Now that It Didn't Do Before. TDR/The Drama Review 61, 4 (Nov. 2017), 78-95. https://doi.org/10.1162/DRAM_a_00693

[67] Yuho Yazaki, Asako Soga, Bin Umino, and Motoko Hirayama. 2015. Automatic Composition by Body-Part Motion Synthesis for Supporting Dance Creation. In 2015 International Conference on Cyberworlds (CW). 200-203. https://doi.org/10.1109/CW.2015.26 